\title{
Evaluation of contrast Sonazoid-enhanced ultrasonography for the detection of hepatic metastases in breast cancer
}

\author{
Mai Mishima • Uhi Toh • Nobutaka Iwakuma • \\ Miki Takenaka $\cdot$ Mina Furukawa $\cdot$ Yoshito Akagi
}

Received: 28 February 2014/ Accepted: 7 August 2014/Published online: 21 August 2014

(C) The Author(s) 2014. This article is published with open access at Springerlink.com

\begin{abstract}
Background The present study was aimed to evaluate the usefulness of contrast Sonazoid-enhanced ultrasonography (US) for the detection of hepatic metastases in breast cancer patients and compare the clinical efficacy and sensitivity of this technique with conventional contrast unenhanced B-mode US in follow-up examinations of breast cancer patients with liver metastasis.

Methods We assessed a total of 84 hepatic tumors from 24 patients diagnosed with or suspected of having metastatic cancer. These hepatic nodules were diagnosed through imaging, including dynamic magnetic resonance imaging (MRI), contrast-enhanced computed tomography (CECT) scan, B-mode US or contrast Sonazoid-enhanced US (SEUS). Differences in the sensitivity between US and SEUS were compared using MR imaging, CECT, and follow-up imaging.

Results A total of 79 nodules were diagnosed as metastatic tumors. The remaining nodules were diagnosed as benign tumors (hepatic hemangioma: $n=3$; local fatty change: $n=2$ ). SEUS precisely detected the presence or absence of hepatic tumors in the 24 patients examined, showing a sensitivity of $98.8 \%$ (83 of 84 lesions) for total imaged solid liver lesions, with an accuracy of $98.7 \%$ (78 of 79 lesions) for total metastatic breast cancer lesions. In contrast, conventional B-mode US imaging revealed hepatic tumor lesions at a sensitivity of $66.7 \%$ (56 of 84 lesions) and an accuracy of $64.6 \%$ (51 of 79 lesions), respectively. Furthermore, the false positive and false
\end{abstract}

M. Mishima · U. Toh $(\bowtie) \cdot$ N. Iwakuma · M. Takenaka •

M. Furukawa · Y. Akagi

Department of Surgery, Kurume University School of Medicine,

67 Asahi-machi, 830-0011 Kurume, Fukuoka, Japan

e-mail: utoh@med.kurume-u.ac.jp negative rates were, respectively, 6.33 and $29.1 \%$ for B-mode US and 0 and $1.3 \%$ for SEUS. Moreover, twentyseven metastatic tumors and five benign lesions ( 3 hemangiomas and 2 focal fatty changes/sparings) were imaged using SEUS but not conventional B-mode US. Significant differences in diagnostic accuracy rates between contrast Sonazoid-enhanced US and conventional B-mode US were observed (Wilcoxon signed rank test: $p=0.0009$ ). No severe adverse events occurred during SEUS after the administration of Sonazoid, except for a grade 1 skin reaction and nausea in one patient.

Conclusion These results suggested that Sonazoid could be safely administrated to breast cancer patients with liver metastatic disease. Thus, contrast Sonazoid-enhanced US is a feasible and more effective method than B-mode US for the detection of hepatic metastasis, particularly for small metastatic breast cancer lesions less than $14 \mathrm{~mm}$ in diameter, showing significant high sensitivity and accuracy.

Keywords Breast cancer - Liver metastasis - B-mode ultrasonography $\cdot$ Contrast Sonazoid-enhanced ultrasonography

\section{Introduction}

Hepatic metastasis is a major problem in breast cancer patients. The detection of these lesions has treatment and prognostic implications, and accurate staging is also a prerequisite for monitoring chemotherapy. Although an abdominal liver ultrasound is not recommended for routine breast cancer surveillance, as to other conventional examinations, ultrasonography has been reported as effective for the "early" detection of hepatic recurrences [1,2]. Despite the recent development of new techniques, including 
18-fluro-2-deoxyglucose (FDG) positron emission tomography (PET) computed tomography (CT) and dynamic magnetic resonance imaging (MRI), for the detection of hepatic metastasis from breast cancer, the use of ultrasonography (US) for the assessment and follow-up of hepatic metastatic disease might benefit from a reliable, easily available, low cost, noninvasive imaging modality. Although B-mode US is commonly performed as a screening examination, most of the conventional US techniques have relatively poor sensitivity and specificity for imaging liver metastases (53-76\%), and transabdominal US is inferior in sensitivity for liver metastases compared with CT or MRI primarily reflecting a lack of contrast agents. Currently CECT and MRI are the only imaging modalities that offer the highest diagnostic potential for the assessment of liver metastases in breast cancer patients $[3,4]$.

Contrast-enhanced US has been demonstrated as a suitable technique for the detection of hepatic malignancy or metastases and is more accurate compared with conventional B-mode US [5-9]. However, the efficacy of contrast-enhanced US for the detection of hepatic metastases from breast cancer has not been specifically evaluated. Sonazoid (Diichi-Sankyo, Tokyo, Japan) is a new microbubble agent that provides a parenchymaspecific contrast image based on its accumulation in the Kupffer cells of the liver [10-14]. Sonazoid has previously been approved for clinical use in Japan, and this agent presents a image in the post-vascular phase $(\mathrm{Ku}-$ pffer image) with a long duration, followed by the images of the arterial phase and the portal phase (vascular phase) $[15,16]$. In the present clinical study, we demonstrate the use of Sonazoid in contrast-enhanced US for the detection of hepatic metastasis in patients with breast cancer.

\section{Patients and methods}

Patients

Between September 2011 and December 2012, 24 female patients (median age 59 years, range 41-72 years) with histologically diagnosed metastatic breast cancer were included in this study. Inclusion criteria were referral to the radiology department for CECT and/or US of the liver for suspected or known hepatic metastases. In addition to the hepatic metastases from primary breast cancer, the other metastatic sites included bone $(n=17)$, lung $(n=8)$, distant lymph nodes $(n=5)$, brain $(n=3)$ and skin-chest wall recurrence $(n=2)$. The median number of sites of metastatic disease before the entry was 3 (range 1-5sites). All patients with metastatic disease were treated with conventional chemotherapy and/or endocrine therapy using weekly paclitaxel with trastuzumab for 3 patients, triweekly docetaxel with trastuzumab for 4 patients, Eribulin for 2 patients and Capecitabine for 1 patient. The remaining 14 patients underwent endocrine therapy, including Tamoxifen for 4 patients and aromatase inhibitor for 10 patients (anastrozoles for 5 patients, letrozoles for 3 patients, and exemestanes for 2 patients). In addition, 3 patients with Her-2 positive metastatic disease also underwent concurrent trastuzumab treatment (Table 1). All patients provided written informed consent for participation in this study.

Table 1 Characteristics of the patients with suspected hepatic metastases and adverse events during SEUS

\begin{tabular}{|c|c|c|}
\hline Characteristics $^{\text {a }}$ & No. & Percentage \\
\hline Age (median) & $\begin{array}{l}59 \text { years old } \\
(41-72)\end{array}$ & \\
\hline \multicolumn{3}{|l|}{ Menopausal status } \\
\hline Premenopause & 4 & $17 \%$ \\
\hline Postmenopause & 20 & $83 \%$ \\
\hline \multicolumn{3}{|l|}{ Intrinsic subtype } \\
\hline Luminal phenotype & 9 & $38 \%$ \\
\hline HER2 phenotype & 9 & $38 \%$ \\
\hline Triple negative phenotype & 6 & $25 \%$ \\
\hline \multicolumn{3}{|l|}{ Sites of metastases beside liver } \\
\hline Bone & 17 & \\
\hline Lung & 8 & \\
\hline Distant lymph nodes & 5 & \\
\hline Brain & 3 & \\
\hline Skin-chest wall recurrence & 2 & \\
\hline \multicolumn{3}{|l|}{ Treatment $^{\mathrm{b}}$} \\
\hline Chemotherapy ( + trastuzumab) & $10(6)$ & $42 \%$ \\
\hline $\begin{array}{l}\text { Endocrine therapy } \\
(+ \text { trastuzumab })\end{array}$ & $14(3)$ & $58 \%$ \\
\hline Adverse event during SEUS & No. & Grade \\
\hline Nausea & 1 & 1 \\
\hline Vomiting & 0 & \\
\hline Diarrhea & 0 & \\
\hline Edema & 0 & \\
\hline Itching & 1 & 1 \\
\hline Skin rush & 0 & \\
\hline Headache & 0 & 0 \\
\hline
\end{tabular}

\footnotetext{
a The median follow-up time was 14.1 months (range 9-28 months)

b The treatment for metastatic disease included chemotherapy with trastuzumab for 6 patients ( 3 patients were treated weekly with Paclitaxel and 4 patients were treated triweekly with docetaxel), endocrine therapy with trastuzumab for 3 patients, Eribulin was administered to 2 patients and Capecitabine was used to treat 1 patient. The remaining eleven patients underwent endocrine therapy only
} 
Imaging techniques, equipments and imaging assessment

All patients underwent conventional US, contrast Sonazoid-enhanced US (SEUS), and CECT or MRI. The metastatic nature of the liver lesions was determined on the basis of progression or remission through imaging after chemotherapy or endocrine therapy. Four experienced radiologists, blinded to any other imaging data, performed the B-mode and SEUS scanning using an Aplio-400 (Toshiba, Tokyo, Japan). The Aplio-400 PVT375BT Transducer/Probe had been used with a $3.5 \mathrm{MHz}$ center frequency. Adverse events occurring up to $24 \mathrm{~h}$ post injection were recorded according to Common Terminology Criteria for Adverse Events (CTCAE version 4.0). The patients received a bolus intravenous injection of Sonazoid $(0.015 \mathrm{~mL} / \mathrm{kg}$ body weight $)$ through a peripheral venous line, followed by $10 \mathrm{~mL}$ of normal saline flush. After the administration of Sonazoid, the portal veins, hepatic veins, and normal liver parenchyma were uniformly enhanced immediately (vascular phase image). Approximately $10 \mathrm{~min}$ after the injection, the liver was scanned again to observe the post-vascular image (Kupffer image). The hepatic metastases were identified as perfusion defects (Fig. 1a) clearly more visible in the post-vascular image than those in the B-mode US (Fig. 1c) or early vascular phase (Fig. 1b) including images of the arterial phase and the portal phase, which were captured less than 10 min after Sonazoid injection. The post-vascular phase image (Kupffer image) lasted at least for $20 \mathrm{~min}$.

A total of 24 patients underwent SEUS in addition to B-mode US. The number and size of the metastases identified through CECT and/or MR were compared with those detected using B-mode US and SEUS. In SEUS, if a lesion showed reduced enhancement (defect/washout), then it was considered metastatic (Fig. 1) and if it showed iso- or hyper-enhancement, then the lesion was considered benign (Fig. 2), compared with the surrounding liver in the post-vascular phase. Hepatic metastases were identified in most cases as perfusion defects in the post-vascular phase image, and this image lasted 10-30 min after the injection of Sonazoid, and in some cases, showed hypoechoic changes with rim enhancement, which also distinguished metastases from most other masses. Based on baseline ultrasonography, metastases were defined as clearly visible round, oval, or lobulated solid focal lesions that were neither simple cysts nor typical of hemangioma, focal fatty sparing or change. In SEUS, metastases were defined as sharply marginated round, oval, or lobulated hypoechoic defects in enhancing parenchyma in the portal venous or post-vascular phase (Kupffer phase). Further, tumor vessels and tumor enhancement of liver metastases were visualized immediately in the early vascular phase (arterial phase) following Sonazoid administration. However, not only relatively large vessels including tumor
Sonazoid-enhanced US

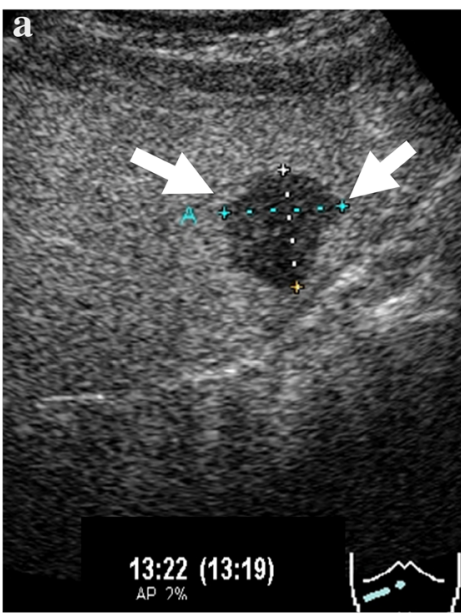

Late Kupffer-phase

(Post-vascular imaging)

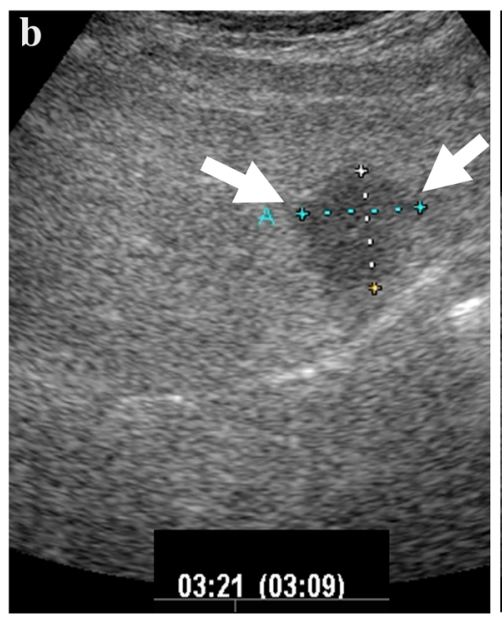

Early Kupffer-phase
B-mode US

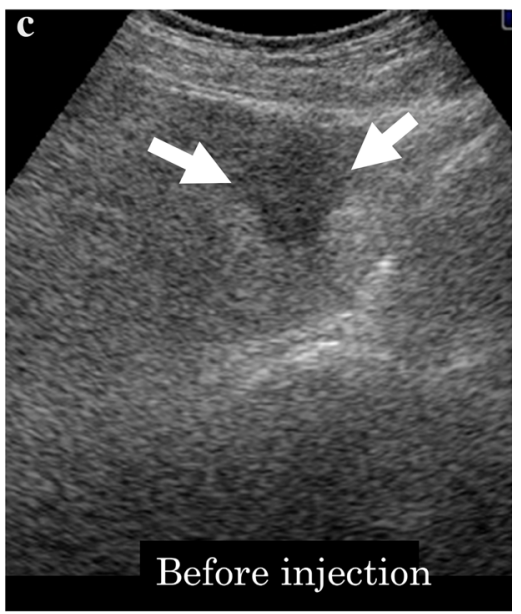

B-mode imaging

(Early vascular imaging)

Fig. 1 More hepatic metastases (arrows) were identified as perfusion defects (a) in the post-vascular phase (Kupffer phase) than at the early vascular phase (b) or before the administration of Sonazoid using conventional B-mode US (c) 


\section{Sonazoid-enhanced US}

\section{B-mode US}

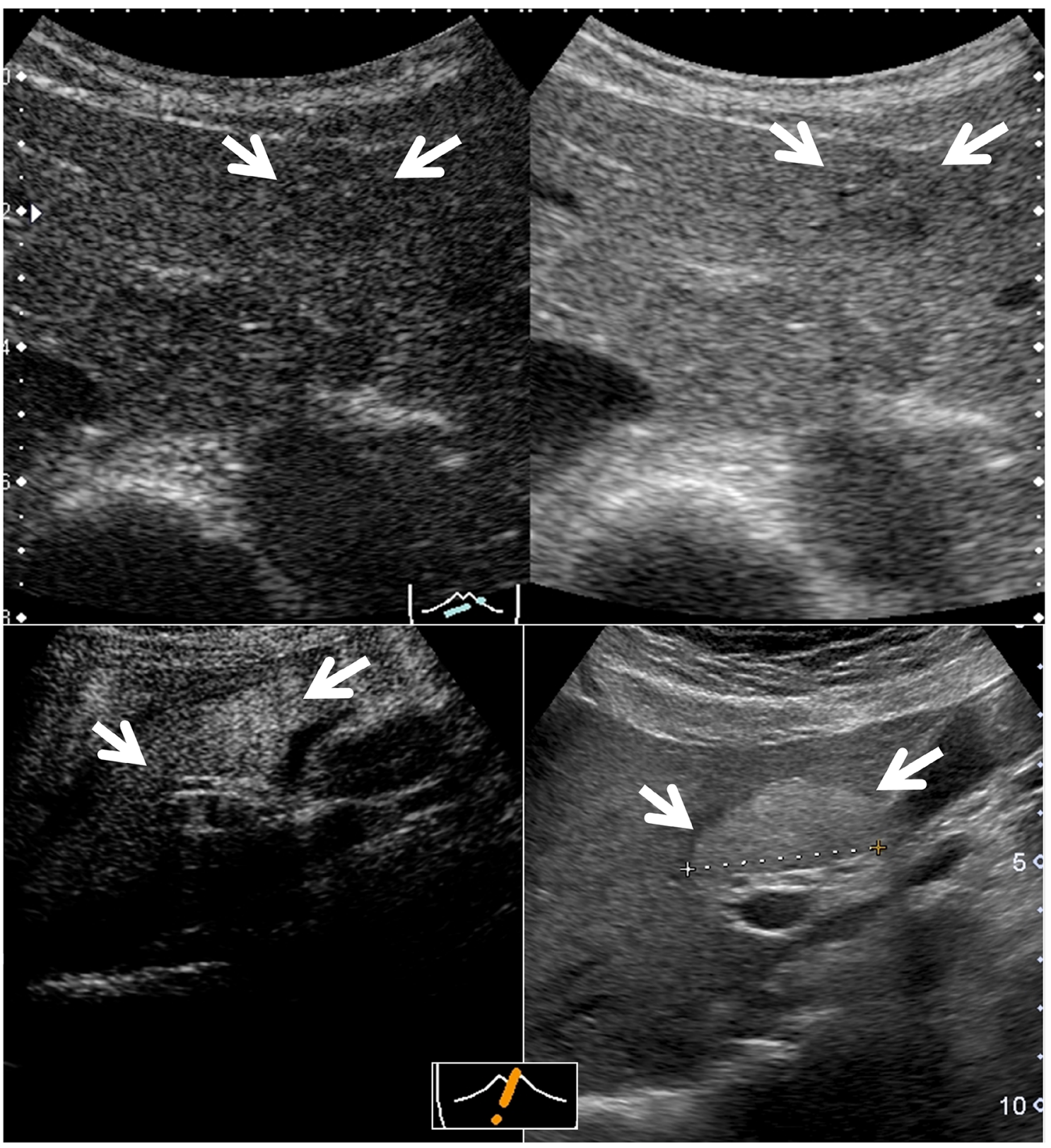

Fig. 2 In SEUS, lesions showing iso-enhancement as a hemangioma (upper) and iso- or hyper-enhancement as a focal fatty change/sparing (below) were considered benign (arrows)

vessels and portal veins, but also microvessels within the liver parenchyma are rapidly fulfilled with Sonazoid microbubbles, which in turn permit rapid enhancement of the tumor and liver parenchyma simultaneously. For each patient, the final number of hepatic metastases present at the time of US and SEUS was determined based on a consensus reading, including the results of MR imaging examination or CECT, US, SEUS, and follow-up imaging examinations.
Statistics analysis

The standard was determined as the number of metastases revealed through a combination of CECT or MRI and follow-up. The sensitivity and accuracy of both types of US for metastases were calculated in the detection of individual metastases for each patient, and the sensitivities were compared using the Wilcoxon signed rank test. A $p$ value of less than 0.05 was considered statistically significant. 


\section{Results}

Clinical results

All twenty-four patients with suspected hepatic metastatic tumors (Table 1) received at least twice Sonazoid injections in each examination, and no general or cardiovascular complications or severe adverse events were observed during the procedure. Only one patient complained of mild nausea (Grade 1) and a skin reaction (Grade1) on the injected site after Sonazoid administration.

Follow-up examinations were performed every 3 months, and equivocal lesions under B-mode US and SEUS were clarified through computed tomography (CT) scan and/or magnetic resonance imaging (MRI). The median follow-up was 14.1 months (range 9-28.2 months).

The total number of suspected metastatic lesions upon initial examination was 84 . A total of 19 patients presented hepatic metastases, detected as a total of 79 metastatic lesions using contrast-enhanced MRI and/or CECT; no metastases were observed in 5 patients. A total of 74 hepatic metastases were observed in 19 patients using CECT. Four lesions were observed using SEUS, but not with CECT; these lesions were revealed as small metastases $(4-14 \mathrm{~mm}$ at the time of the diagnosis) upon follow-up imaging, showing an increase in lesion size (Fig. 3). There was no exclusion based on poor ultrasonographic conditions, and the population included a total of 79 hepatic metastases in 19 patients. SEUS revealed 78 out of 79 metastases with tumor sizes ranging from 4 to $174 \mathrm{~mm}$ in diameter. One lesion was missed using both US and SEUS detection methods compared with the MRI findings; this subdiaphragmatic lesion was not accessible to ultrasonography. SEUS showed more MRI-confirmed metastatic lesions, detecting 83 of the 84 lesions with $98.8 \%$ sensitivity, compared with conventional US, which only detected 56 lesions in 11 of the 19 patients, with $66.7 \%$ sensitivity. SEUS and conventional US revealed suspected malignant breast cancer metastases in a total of 78 and 51

\section{CECT / SEUS}

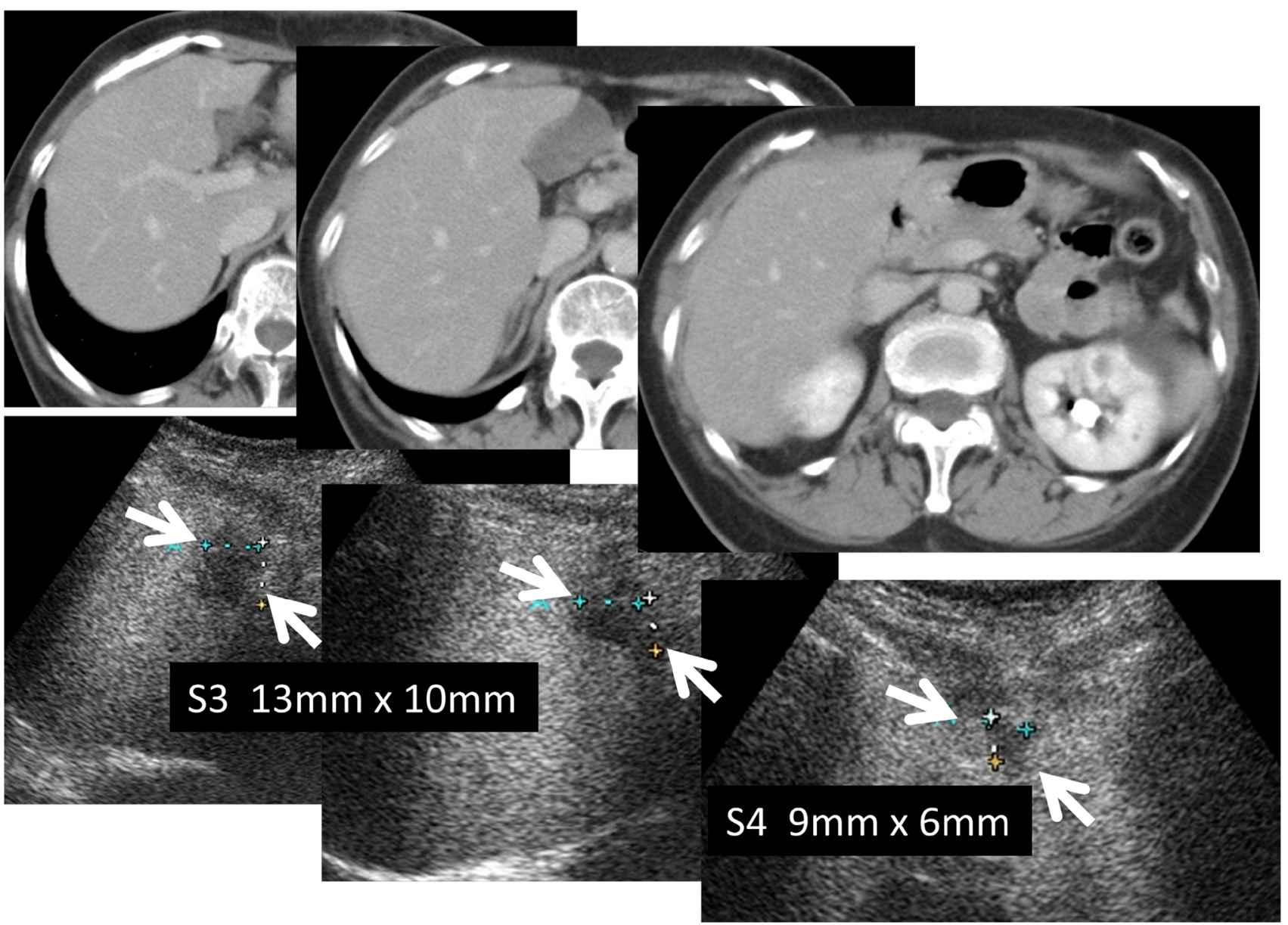

Fig. 3 Four lesions were observed with SEUS (below arrows) but not with CECT (upper). Three of the four lesions were shown to be small metastases (4-13 $\mathrm{mm}$ at the time of the diagnosis) during follow-up imaging, reflecting the increase in lesion size 
lesions, respectively, and the true positive rates (accuracy) were $98.7 \%(78 / 79)$ and $64.6 \%$ (51/79), respectively (Wilcoxon signed rank test $p=0.0009$ ) (Table 2).

The mean maximum diameter of the lesions was $32 \mathrm{~mm}$ (range 4-174 mm). The lesions missed using B-mode US and detected with SEUS had a median maximum diameter of $14 \mathrm{~mm}$, ranging from 4 to $17 \mathrm{~mm}$ (Fig. 4). The average sensitivity for the detection of individual metastases improved significantly from 66.7 to $98.8 \%$ (Wilcoxon signed rank test $p=0.0112$ ). False-positive results were identified in five lesions in five different patients using conventional B-mode US; three lesions were hepatic hemangiomas and two lesions were focal fatty change/sparing (Fig. 2), diagnosed through SEUS, CECT and confirmed upon follow-up imaging. No false-positives results were observed with SEUS. However, four lesions were missed under CECT scan examination and detected only through SEUS, likely reflecting the small size of the lesion, with a diameter of less than $13 \mathrm{~mm}$ (Fig. 3). Only one patient, showing false negative rates using SEUS (also on B-mode US), presented a subdiaphragmatic lesion that was not typically accessible to ultrasonography. Large metastatic lesions were markedly enhanced in the postvascular phase (Kupffer phase), either homogeneously or peripherally. In the post-vascular phase, the liver metastases in breast cancer patients showed hypoenhancing or perfusion defects in 65 of 79 lesions (82.3\%) (Fig. 5), in contrast, fourteen of the 79 lesions $(17.7 \%)$ displayed hypoechoic changes with rim enhancement (Fig. 6).

\section{Discussion}

In the present study, we demonstrated that liver metastasis from breast cancer frequently shows hypoechoic defects under contrast Sonazoid-enhanced US compared with the surrounding normal liver parenchyma enhanced through increased echogenicity resulting from treatment with a Sonazoid microbubble contrast enhancer (Fig. 1).

Small liver metastases from breast cancer were only detected through contrast Sonazoid-enhanced US, and conventional US did not show abnormality in metastatic lesions ranging from 4 to $17 \mathrm{~mm}$ in diameter. Similarly, CECT did not detect micrometastatic lesions of less than $13 \mathrm{~mm}$ in diameter. In contrast, SEUS at the post-vascular phase (Kupffer imaging) revealed 4-17 mm rounded small hepatic metastatic lesions (Figs. 3 and 4), compared with CECT scan showed a low sensitivity for detection and characterization of lesions smaller than $1 \mathrm{~cm} \mathrm{[17];} \mathrm{con-}$ trast-enhanced US had detected small hepatic metastatic lesions $(<1 \mathrm{~cm})$ with a high sensitivity [18]; and in this study, four additional small lesions had been revealed by SEUS, but not by CECT. These results suggest SEUS has better contrast resolution than CECT for detecting small hepatic metastatic lesions, and SEUS may improve the detection of miliary metastases $(0.5-1 \mathrm{~cm})$ [19].

The detection of large liver metastases from breast cancer using conventional B-mode US and SEUS in the post-vascular phase, revealed that $82.3 \%$ of most enhanced lesions showed reduced enhancement (defect/ washout) (Fig. 5), and $17.7 \%$ of the lesions showed hypoechoic changes with rim enhancement in the postvascular phase using SEUS, which was not visible through baseline ultrasound (Fig. 6).

In the present study, contrast Sonazoid-enhanced US showed higher sensitivity and accuracy for the detection of liver metastases from breast cancer compared with conventional unenhanced B-mode US. Several clinical trials involving contrast-enhanced US using Sonazoid to detect hepatic metastasis have been performed worldwide in
Table 2 Results of Sonazoidenhanced ultrasonography for patients with hepatic metastasis of breast cancer

a 24 patients with total 84 hepatic tumors having or suspected of having metastatic cancer from breast cancer

b 19 patients with a total 79 metastatic breast cancer (MBC) lesions, diagnosed through contrast-enhanced MRI and/or CECT

c Statistical significance

\begin{tabular}{|c|c|c|c|c|c|c|}
\hline & B-mode & Sonazoid & CECT & MRI & $\begin{array}{l}\text { B-mode } \\
\text { No. false } \\
\text { positive cas }\end{array}$ & $\begin{array}{l}\text { Sonazoid } \\
\text { ses }\end{array}$ \\
\hline Total lesions of suspected metastases ${ }^{\mathrm{a}}$ & 84 & 84 & 84 & 84 & & \\
\hline Total detected lesion & 56 & 83 & 80 & 84 & & \\
\hline Total lesions of $\mathrm{MBC}^{\mathrm{b}}$ & 79 & 79 & 79 & 79 & & \\
\hline Detected No. MBC & 51 & 78 & 75 & 79 & & \\
\hline Detected No. other diseases & & & & & 5 & 0 \\
\hline Hemangioma & 0 & 3 & 3 & 3 & 3 & 0 \\
\hline Focal fatty change & 0 & 2 & 2 & 2 & 2 & 0 \\
\hline Sensitivity $(\%)^{\mathrm{c}}$ & 66.7 & 98.8 & 95.2 & 100 & & \\
\hline Accuracy $(\%)^{\mathrm{c}}$ & 64.6 & 98.7 & 94.9 & 100 & & \\
\hline Positive predictive rate $(\%)$ & 70.9 & 98.7 & & & & \\
\hline False positive rate $(\%)$ & & & & & 6.3 & 0 \\
\hline False negative rate $(\%)$ & 29.1 & 1.3 & & & & \\
\hline
\end{tabular}




\section{Sonazoid-enhanced US}

\section{B-mode US}

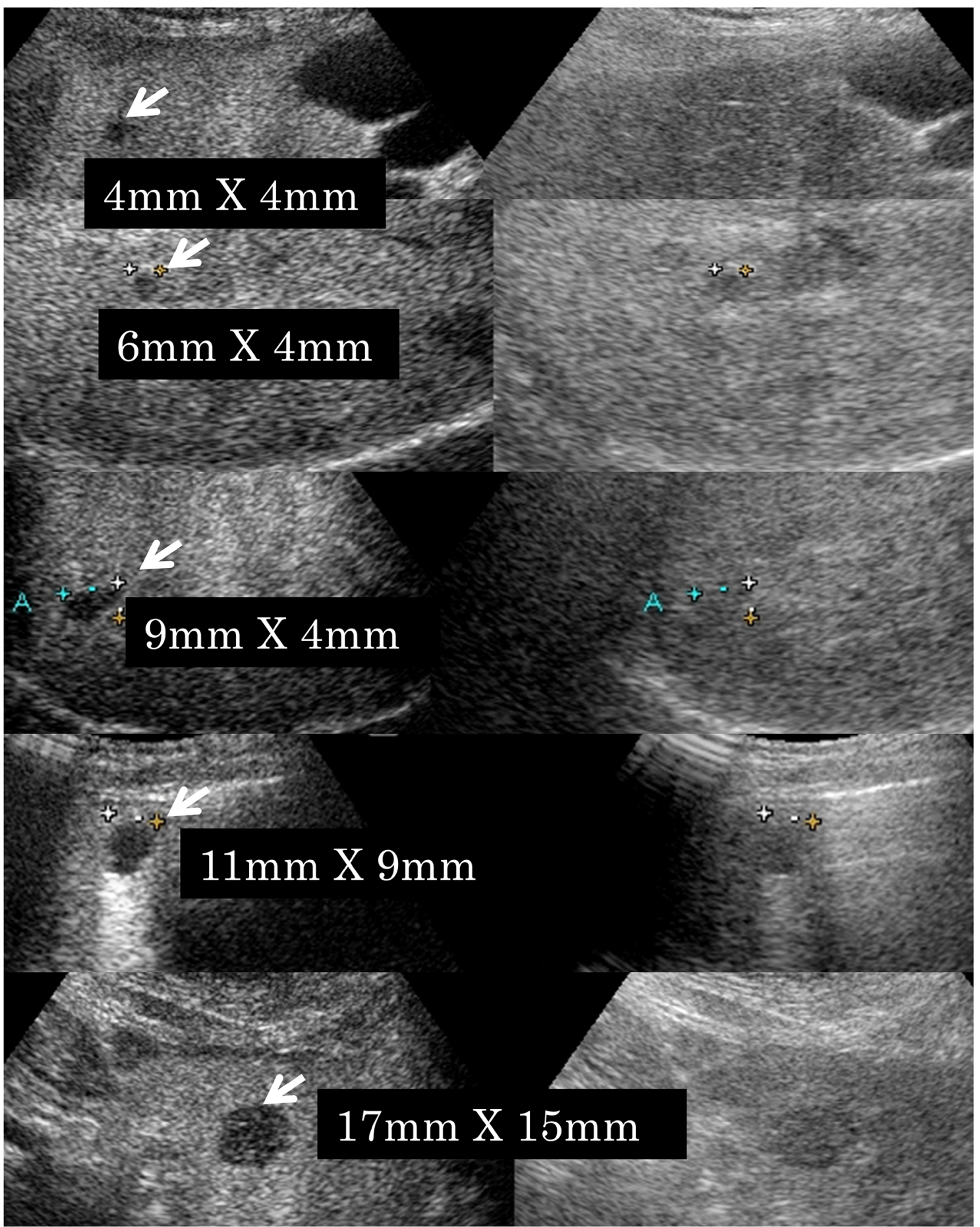

Fig. 4 The lesions missed with US and detected with SEUS (white arrows) ranged in size from 4 to $17 \mathrm{~mm}$, with an average maximum diameter of $14 \mathrm{~mm}$

various cancers [9, 20-22] and these previous studies have also demonstrated the improvement in accuracy of contrast-enhanced US in diagnosing hepatic metastasis [2325]. Differential diagnosis of hepatic metastasis between breast cancer and other original cancer may indeed be a problem, there were some reports demonstrating that hepatic cellular carcinoma shows increased enhancement in the arterial phase, metastasis from gastrointestinal 


\section{Sonazoid-enhanced US / B-mode US}

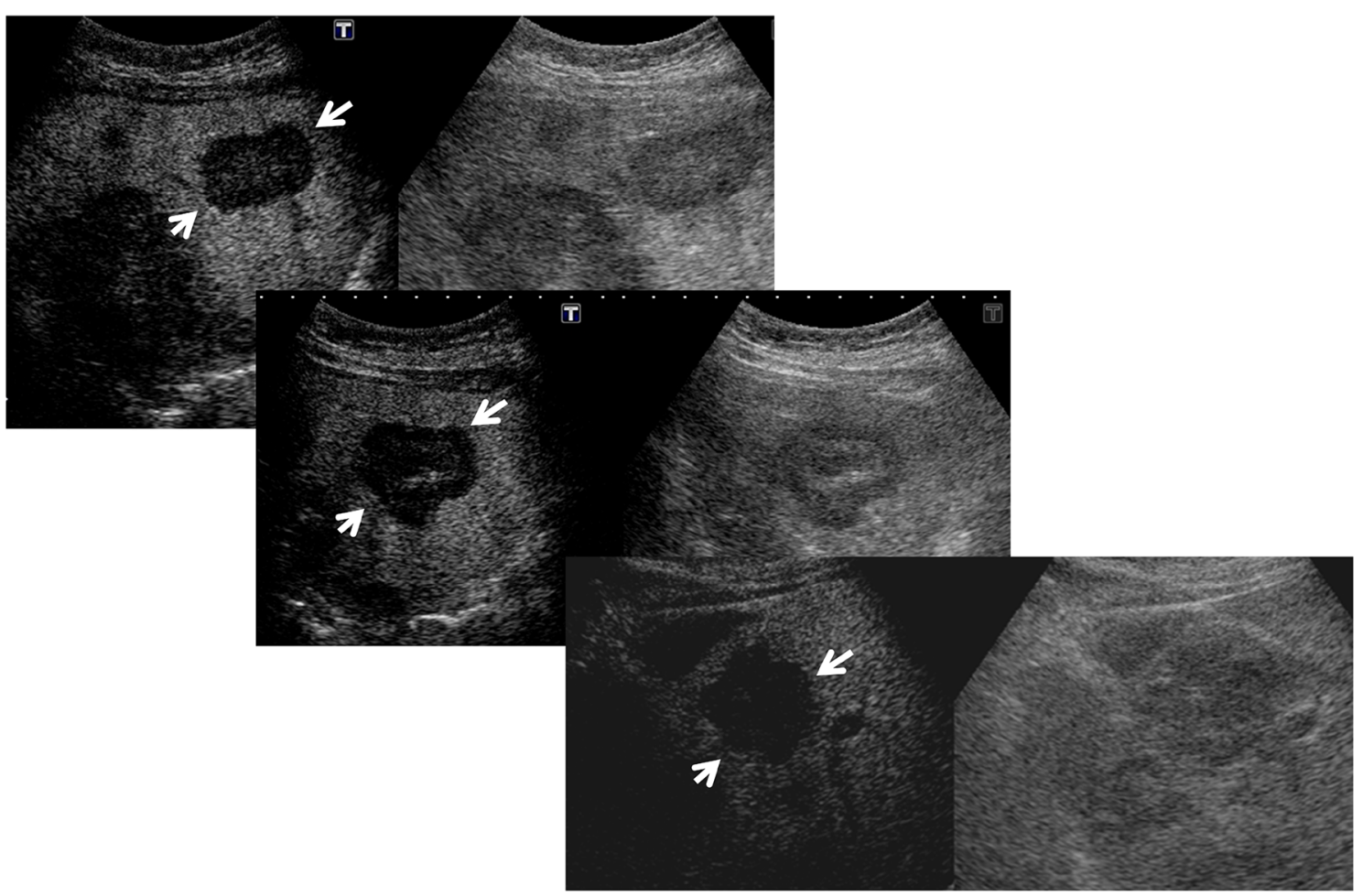

Fig. 5 Approximately $82.3 \%$ of the liver metastases of breast cancer showed hypoenhancing or filling defects (white arrows) in the postvascular phase

cancer and neuroendocrine tumor can be identified with the hypoenhancement in the portal venous and the post-vascular phase [22]. However, as far as we know, no published study has specifically reported the value of SEUS for detecting hepatic liver metastases from breast cancers.

Contrast-enhanced ultrasound with Sonazoid detected significantly more metastases compared with conventional US, with a sensitivity of 98.8 versus $66.7 \%$. However, SEUS revealed no additional patients with metastatic disease. The hepatic metastases detected through SEUS were indeed relatively small lesions (4-17 $\mathrm{mm}$ ), often associated with larger lesions. The detection of hepatic metastases from breast cancer using conventional US is limited by the relatively small difference in background patterns between the lesions and hepatic parenchyma, resulting in poor contrast differentiation between the two tissues, likely reflecting the difficulty in definitively diagnosing liver hemangioma and focal fatty change/sparing lesions using only B-mode US. The use of an ultrasound contrast agent such as Sonazoid increases the echogenicity of the liver at the post-vascular specific phase as the microbubbles accumulate in the normal parenchyma.

Although we did not specifically compare the value of the different vascular phases in the detection of metastases from breast and other cancers, the post-vascular phase image (Kupffer image) was valuable, as $83.3 \%$ of the metastases from breast cancer were perfusion defects in the parenchyma, and $17.7 \%$ of breast cancer metastases was iso- or hypoechoic compared with liver parenchyma, showing hypoechoic changes with rim enhancement in the post-vascular phase. However, we did not confirm this finding quantitatively because only 14 of the 79 lesions detected showed central necrotic hypoechoic changes. Notably, the internal content of the metastatic lesions or the areas showing necrotic changes were also correctly identified using SEUS. Because the data from the 19 patients subjected to CECT was limited, the difference between SEUS and CECT scan imaging was not significant in this study. Four lesions were missed by dynamic CT scan examination, but these lesions were identified using SEUS, likely reflecting the small size of the lesion. However, one patient, who showed false-negative results after both baseline B-mode and SEUS, had a subdiaphragmatic lesion that was not accessible to sonography. The limitations of dynamic CT scanning make it difficult to detect small metastases, and the limitations of US make it difficult to visualize subdiaphragmatic lesions.

Furthermore, ultrasound contrast agents, including Sonazoid modify the basic physical interactions between ultrasound waves and hepatic tissues and amplify the signal 


\section{Sonazoid-enhanced US}

\section{B-mode US}
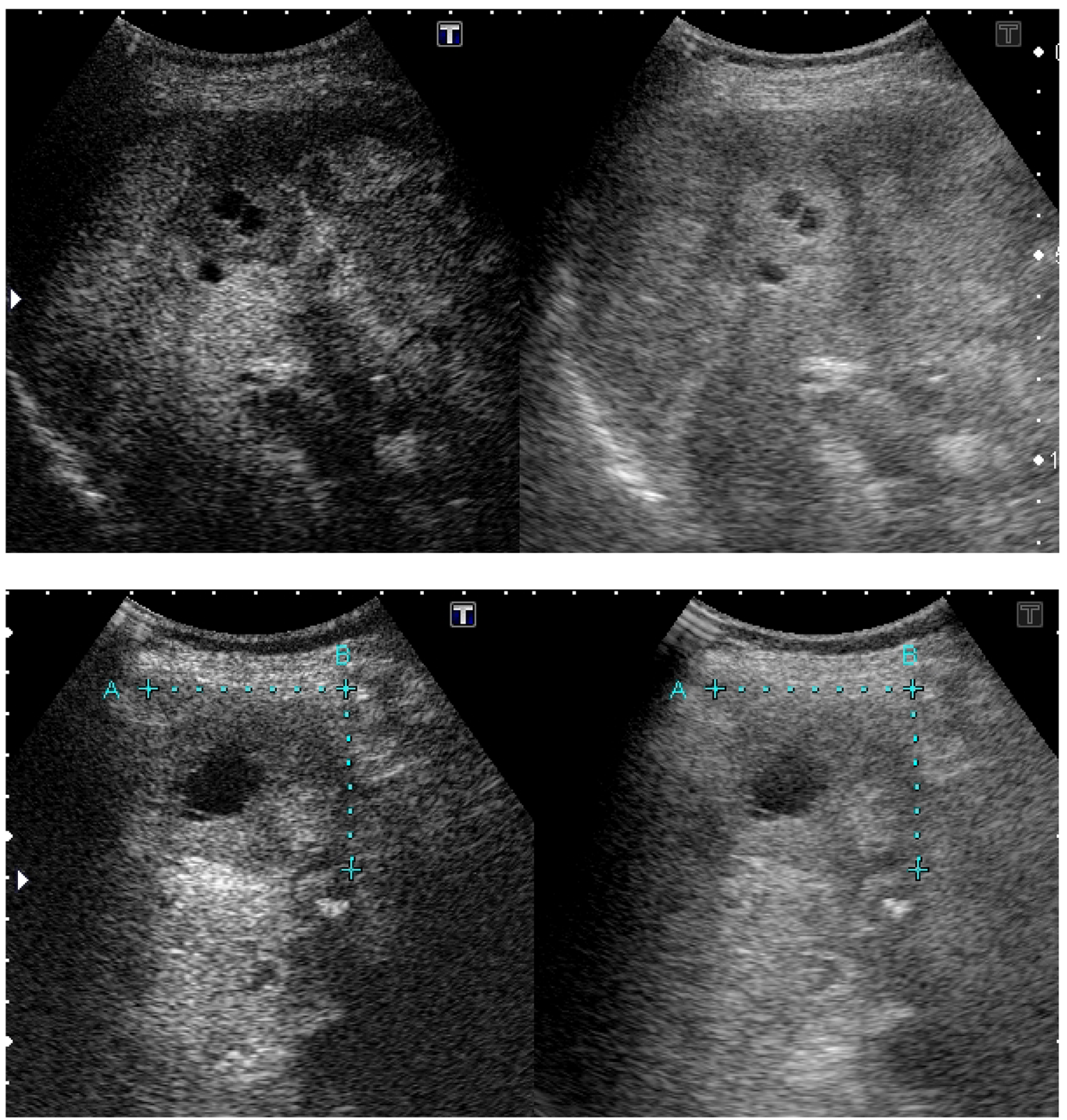

Fig. 6 Approximately $17.7 \%$ of the liver metastases of breast cancer displayed hypoechoic changes with rim enhancement in the post-vascular phase

produced by flowing blood. Thus, Sonazoid might be useful for detecting subtle flow abnormalities and distinguishing areas of abnormal flow relative to normal background parenchymal perfusion. As a result, these contrast agents might improve the characterization of focal liver lesions compared with standard B-mode US, while providing complementary information with other imaging modalities [26-28]. In the present study, we also demonstrated using contrast Sonazoid-enhanced US for the adequate detection of benign lesions, including three hepatic hemangiomas and two focal fatty changes, in patients with metastatic breast cancer.

Thus, these results suggest that SEUS, followed by conventional B-mode US for evaluating breast cancer metastases, might not only be used to successfully detect malignant lesions with higher sensitivity and accuracy, but also to identify benign lesions, including hepatic hemangioma or focal fatty changes, for the differential diagnosis of hepatic lesions. Moreover, because it is competitive, cost effective and less invasive, SEUS technique used for 
follow-up of hepatic metastases from breast cancer may be an alternative to other imaging modalities including CT scan and MRI. Consequently, the development of a new SEUS approach could improve the diagnostic sensitivity and detection accuracy for hepatic breast cancer metastases and could also provide important information for making treatment decisions for patients with breast cancer.

These results were presented at the 72nd Annual Meeting of the Japanese Breast Cancer Society in June 2013.

Acknowledgments The authors would like to thank Mrs. U. Hori, T. Aizono and Y. Takahashi at Kurume University Hospital for assistance in ultrasonography.

Conflict of interest All authors did not have conflict of interest.

Open Access This article is distributed under the terms of the Creative Commons Attribution License which permits any use, distribution, and reproduction in any medium, provided the original author(s) and the source are credited.

\section{References}

1. Khatcheressian JL, Hurley P, Bantug E, Esserman LJ, Grunfeld E, Halberg F, et al. Breast cancer follow-up and management after primary treatment: american society of clinical oncology clinical practice guideline update. J Clin Oncol. 2013;31(7):961-5 (PubMed PMID: 23129741).

2. Nicolini A, Carpi A, Ferrari P, Anselmi L, Spinelli C, Conte M, et al. The role of tumour markers in improving the accuracy of conventional chest X-ray and liver echography in the post-operative detection of thoracic and liver metastases from breast cancer. $\mathrm{Br} J$ Cancer. 2000;83(11):1412-7 (PubMed PMID: 11076646. Pubmed Central PMCID: PMC2363419. Epub 2000/11/15. eng).

3. Hagspiel KD, Neidl KF, Eichenberger AC, Weder W, Marincek B. Detection of liver metastases: comparison of superparamagnetic iron oxide-enhanced and unenhanced MR imaging at $1.5 \mathrm{~T}$ with dynamic CT, intraoperative US, and percutaneous US. Radiology. 1995;196(2):471-8 (PubMed PMID: 7617863. Epub 1995/08/01. eng).

4. Robinson PJ. Imaging liver metastases: current limitations and future prospects. Br J Radiol. 2000;73(867):234-41 (PubMed PMID: 10817037. Epub 2000/05/19. eng).

5. Dietrich CF, Kratzer W, Strobe D, Danse E, Fessl R, Bunk A, et al. Assessment of metastatic liver disease in patients with primary extrahepatic tumors by contrast-enhanced sonography versus CT and MRI. World J Gastroenterol. 2006;12(11):1699-705 (PubMed PMID: 16586537. Epub 2006/04/06. eng).

6. Quaia E, D'Onofrio M, Palumbo A, Rossi S, Bruni S, Cova M. Comparison of contrast-enhanced ultrasonography versus baseline ultrasound and contrast-enhanced computed tomography in metastatic disease of the liver: diagnostic performance and confidence. Eur radiol. 2006;16(7):1599-609 (PubMed PMID: 16552507. Epub 2006/03/23. eng).

7. Albrecht T, Blomley MJ, Burns PN, Wilson S, Harvey CJ, Leen $\mathrm{E}$, et al. Improved detection of hepatic metastases with pulseinversion US during the liver-specific phase of SHU 508A: multicenter study. Radiology. 2003;227(2):361-70 (PubMed PMID: 12649417. Epub 2003/03/22. eng).
8. Larsen LP, Rosenkilde M, Christensen H, Bang N, Bolvig L, Christiansen $\mathrm{T}$, et al. Can contrast-enhanced ultrasonography replace multidetector-computed tomography in the detection of liver metastases from colorectal cancer? Eur J Radiol. 2009;69(2):308-13 (PubMed PMID: 18068925. Epub 2007/12/11. eng).

9. Piscaglia F, Corradi F, Mancini M, Giangregorio F, Tamberi S, Ugolini G, et al. Real time contrast enhanced ultrasonography in detection of liver metastases from gastrointestinal cancer. BMC Cancer. 2007;7:171 (Pubmed Central PMCID: PMC2000899. Epub 2007/09/05. eng).

10. Forsberg F, Piccoli CW, Liu JB, Rawool NM, Merton DA, Mitchell DG, et al. Hepatic tumor detection: MR imaging and conventional US versus pulse-inversion harmonic US of NC100100 during its reticuloendothelial system-specific phase. Radiology. 2002;222(3):824-9 (PubMed PMID: 11867808. Epub 2002/02/28. eng).

11. Kindberg GM, Tolleshaug H, Roos N, Skotland T. Hepatic clearance of Sonazoid perfluorobutane microbubbles by Kupffer cells does not reduce the ability of liver to phagocytose or degrade albumin microspheres. Cell Tissue Res. 2003;312(1):49-54 (PubMed PMID: 12712317. Epub 2003/04/25. eng).

12. Yanagisawa K, Moriyasu F, Miyahara T, Yuki M, Iijima H. Phagocytosis of ultrasound contrast agent microbubbles by $\mathrm{Ku}-$ pffer cells. Ultrasound Med Biol. 2007;33(2):318-25 (PubMed PMID: 17207907. Epub 2007/01/09. eng).

13. Hatanaka K, Kudo M, Minami Y, Ueda T, Tatsumi C, Kitai S, et al. Differential diagnosis of hepatic tumors: value of contrastenhanced harmonic sonography using the newly developed contrast agent, Sonazoid. Intervirology. 2008;51(Suppl 1):61-9 (PubMed PMID: 18544950. Epub 2008/06/27. eng).

14. Sugimoto K, Shiraishi J, Moriyasu F, Doi K. Computer-aided diagnosis of focal liver lesions by use of physicians' subjective classification of echogenic patterns in baseline and contrastenhanced ultrasonography. Acad Radiol. 2009;16(4):401-11 (PubMed PMID: 19268851. Epub 2009/03/10. eng).

15. Watanabe R, Matsumura M, Munemasa T, Fujimaki M, Suematsu M. Mechanism of hepatic parenchyma-specific contrast of microbubble-based contrast agent for ultrasonography: microscopic studies in rat liver. Invest Radiol. 2007;42(9):643-51 (PubMed PMID: 17700280. Epub 2007/08/19. eng).

16. Achmad A, Taketomi-Takahashi A, Tsushima Y. Current developments and clinical applications of bubble technology in Japan: a report from 85th Annual Scientific Meeting of The Japan Society of Ultrasonic in Medicine, Tokyo, 25-27 May. Med Ultrason. 2013;15(2):140-6 (PubMed PMID: 23702504. Epub 2013/05/25. eng).

17. Sahani DV, Kalva SP. Imaging the liver. Oncologist. 2004;9(4):385-97 (PubMed PMID: 15266092. Epub 2004/07/22. eng).

18. Correas JM, Low G, Needleman L, Robbin ML, Cosgrove D, Sidhu PS, et al. Contrast enhanced ultrasound in the detection of liver metastases: a prospective multi-centre dose testing study using a perfluorobutane microbubble contrast agent (NC100100). European radiology. 2011;21(8):1739-46 (PubMed PMID: 21479856. Epub 2011/04/12. eng).

19. Solbiati L, Tonolini M, Cova L, Goldberg SN. The role of contrast-enhanced ultrasound in the detection of focal liver lesions. Eur radiol. 2001;11(Suppl 3):E15-26 (PubMed PMID: 11793049. Epub 2002/01/17. eng).

20. Kitamura H, Koike S, Nakazawa K, Matsumura H, Yokoi K, Nakagawa $\mathrm{K}$, et al. A reversal in the vascularity of metastatic liver tumors from colorectal cancer after the cessation of chemotherapy plus bevacizumab: contrast-enhanced ultrasonography and histological examination. J Surg Oncol. 2013;107(2):155-9 (PubMed PMID: 22903532. Epub 2012/08/21. eng). 
21. Cantisani V, Ricci P, Erturk M, Pagliara E, Drudi F, Calliada F, et al. Detection of hepatic metastases from colorectal cancer: prospective evaluation of gray scale US versus SonoVue(R) low mechanical index real time-enhanced US as compared with multidetector-CT or Gd-BOPTA-MRI. Ultraschall Med. 2010;31(5):500-5 (PubMed PMID: 20408122. Epub 2010/04/22. eng).

22. Claudon M, Dietrich CF, Choi BI, Cosgrove DO, Kudo M, Nolsoe CP, et al. Guidelines and good clinical practice recommendations for contrast enhanced ultrasound (CEUS) in the liver-update 2012: a WFUMB-EFSUMB initiative in cooperation with representatives of AFSUMB AIUM, ASUM, FLAUS and ICUS. Ultraschall Med. 2013;34(1):11-29 (PubMed PMID: 23129518. Epub 2012/11/07. eng).

23. von Herbay A, Vogt C, Haussinger D. Late-phase pulse-inversion sonography using the contrast agent levovist: differentiation between benign and malignant focal lesions of the liver. AJR Am J Roentgenol. 2002;179(5):1273-9 (PubMed PMID: 12388513. Epub 2002/10/22. eng).

24. Harvey CJ, Blomley MJ, Eckersley RJ, Cosgrove DO, Patel N, Heckemann RA, et al. Hepatic malignancies: improved detection with pulse-inversion US in late phase of enhancement with SH U
508A-early experience. Radiology. 2000;216(3):903-8 (PubMed PMID: 10966730. Epub 2000/08/31. eng).

25. Tanaka S, Ioka T, Oshikawa O, Hamada Y, Yoshioka F. Dynamic sonography of hepatic tumors. AJR Am J Roentgenol. 2001;177(4):799-805 (PubMed PMID: 11566675. Epub 2001/09/ 22. eng).

26. Horie S, Chen R, Li L, Mori S, Kodama T. Contrast-enhanced high-frequency ultrasound imaging of early stage liver metastasis in a preclinical mouse model. Cancer Lett. 2013;339(2):208-13 (PubMed PMID: 23791880. Epub 2013/06/25. eng).

27. Shimada T, Maruyama H, Sekimoto T, Kamezaki H, Takahashi $\mathrm{M}$, Yokosuka O. Heterogeneous staining in the liver parenchyma after the injection of perflubutane microbubble contrast agent. Ultrasound Med Biol. 2012;38(8):1317-23 (PubMed PMID: 22698509. Epub 2012/06/16. eng).

28. Shindoh J, Seyama Y, Umekita N. Three-dimensional staining of liver segments with an ultrasound contrast agent as an aid to anatomic liver resection. J Am Coll Surg. 2012;215(2):e5-10 (PubMed PMID: 22683072. Epub 2012/06/12. eng). 